\title{
The Interaction of Endothelial Nitric Oxide Synthase Polymorphism and Current Smoking in Terms of Increased Arterial Stiffness
}

\author{
O. MAYER JR. ${ }^{1}$, J. FILIPOVSKÝ ${ }^{1}$, M. PEŠTA ${ }^{1}$, R. CÍFKOVÁ ${ }^{2}$, M. DOLEJŠOVÁ ${ }^{1}$, \\ J. ŠIMON ${ }^{1}$
}

${ }^{1}$ Second Department of Internal Medicine, Charles University, Medical Faculty and University Hospital, Plzeň, Czech Republic, ${ }^{2}$ Department of Preventive Cardiology, Institute for Clinical and Experimental Medicine, Prague, Czech Republic

Received March 14, 2009

Accepted November 3, 2009

On-line November 20, 2009

\begin{abstract}
Summary
Nitric oxide belongs to the most important factors influencing structural and functional properties of vessel wall. Both genetic and environmental factors may influence its metabolism. The aim of this study was to explore whether two common polymorphisms of endothelial nitric synthase (eNOS) may, jointly with smoking, influence the stiffness of large arteries, quantified as pulse wave velocity (PWV). One hundred ninety four subjects free of manifest atherosclerotic disease or chronic pharmacotherapy were selected from population-based postMONICA study. PWV's were measured using Sphygmocor ${ }^{\circledR}$ device between carotic and femoral arteries (aortic PWV) and between femoral and tibialis-posterior arteries (peripheral PWV). Two common polymorphisms, T786C and G894T, were assessed. Among current smokers, homo- or heterozygous carriers of T786C mutation showed significantly higher peripheral PWV than normal genotype carriers ( 14.0 vs $10.7 \mathrm{~m} / \mathrm{s}, \mathrm{p}<0.002$ ); the same was true for the carriers of G894T mutation (13.9 vs $11.0 \mathrm{~m} / \mathrm{s}$, $\mathrm{p}<0.015)$. No differences were found in non-smokers, and neither of the eNOS polymorphisms influenced aortic PWV in our setting. In conclusion, genetically determined disorder of nitric oxide metabolism was associated with increased stiffness of peripheral, muscular-type arteries in generally healthy, untreated subjects, but only in the interaction with current smoking.
\end{abstract}

\section{Key words}

Pulse wave velocity • Nitric oxide synthase • T786C • G894T • Polymorphism • Smoking

\section{Corresponding author}

O. Mayer Jr., University Hospital, Second Department of Internal Medicine, E. Beneše 13, 32000 Plzeň, Czech Republic. Fax: +420 377420 650. E-mail: mayero@fnplzen.cz

\section{Introduction}

Progressive arterial stiffening is an important manifestation of vascular ageing. Carotid-femoral pulse wave velocity, a measure of stiffness of central elastictype arteries, was repeatedly reported as a powerful predictor of cardiovascular events and mortality (Laurent et al. 2001, Meaume et al. 2001). The stiffness of central arteries (aorta) depends mainly on elastin and collagen content and is strongly influenced by age. In large and medium-sized muscular arteries (such as lower and upper limb vascular bed, iliac artery, etc.), stiffness is influenced by distending transmural pressure (mean arterial pressure) and by the tone of vascular smooth muscles; age-dependent changes in elastin and collagen content are of lesser importance than in central elastic arteries. Nitric oxide (NO) probably participates in the functional regulation of arterial stiffness. Beside several other physiological properties, NO also relaxes vascular smooth muscle and modulates migration and growth of vascular smooth muscle cells (Localzo et al. 1995), which strongly relates to functionally and structurally underlined stiffness of muscular-type arteries.

Endothelium-derived NO is synthesized from

PHYSIOLOGICAL RESEARCH • ISSN 0862-8408 (print) • ISSN 1802-9973 (online)

(c) 2010 Institute of Physiology v.v.i., Academy of Sciences of the Czech Republic, Prague, Czech Republic

Fax +420 241062 164, e-mail: physres@biomed.cas.cz,www.biomed.cas.cz/physiolres 
Table 1. Clinical characteristics of study sample and allele frequencies of eNOS polymorphisms.

\begin{tabular}{|c|c|}
\hline$n$ & 194 \\
\hline Male gender (\%) & 48.5 \\
\hline Age (years) & $45.7 \pm 10.86$ \\
\hline Current smoking (\%) & 36.1 \\
\hline Ex-smoking (\%) & 14.4 \\
\hline Body mass index $\left(\mathrm{kg} / \mathrm{m}^{2}\right)$ & $26.0 \pm 4.09$ \\
\hline Systolic blood pressure ( $\mathrm{mm} \mathrm{Hg}$ ) & $123.0 \pm 15.32$ \\
\hline Ddiastolic blood pressure ( $\mathrm{mm} \mathrm{Hg}$ ) & $79.1 \pm 9.49$ \\
\hline Hypertension ${ }^{l}(\%)$ & 22.2 \\
\hline Total cholesterol (mmol/l) & $5.76 \pm 1.17$ \\
\hline LDL cholesterol (mmol/l) & $3.60 \pm 1.02$ \\
\hline HDL cholesterol (mmol/l) & $1.45 \pm 0.38$ \\
\hline Triglycerides (mmol/l) & $1.59 \pm 0.87$ \\
\hline Hypercholesterolemia $^{2}(\%)$ & 75.8 \\
\hline Fasting glucose $(\mathrm{mmol} / \mathrm{l})$ & $5.44 \pm 1.03$ \\
\hline Homocysteine ( $\mu \mathrm{mol} / \mathrm{l})$ & $11.4 \pm 4.31$ \\
\hline Peripheral PWV $(\mathrm{m} / \mathrm{s})$ & $12.88 \pm 8.41$ \\
\hline Aortic PWV $(\mathrm{m} / \mathrm{sec})$ & $7.40 \pm 2.43$ \\
\hline \multicolumn{2}{|l|}{ T786C polymorphism: } \\
\hline TT genotype (n (\%)) & $84(43.3 \%)$ \\
\hline TC genotype (n (\%)) & $80(41.2 \%)$ \\
\hline CC genotype (n (\%)) & $30(15.5 \%)$ \\
\hline \multicolumn{2}{|l|}{ G894T polymorphism: } \\
\hline TT genotype (n (\%)) & $95(49.0 \%)$ \\
\hline TC genotype (n (\%)) & $86(44.3 \%)$ \\
\hline CC genotype (n (\%)) & $13(6.7 \%)$ \\
\hline
\end{tabular}

${ }^{1}$ blood pressure $\geq 140 / 90 \mathrm{~mm} \mathrm{Hg} ;{ }^{2}$ total cholesterol $\geq 5 \mathrm{mmol} / \mathrm{l}$ and/or LDL cholesterol $\geq 3 \mathrm{mmol} / \mathrm{l}$; mean S.D.

L- arginine by endothelial nitric oxide synthase (Moncada et al. 1991) (eNOS), which is encoded by NOS3 gene on chromosome 7 (Janssens et al. 1992). The functional alteration of NO pathway may be caused by genetically determined eNOS abnormalities and/or by (exo- or endogenous) factors reducing bioavailability of NO, i.e. impairing its physiological properties. There are two common variants of NOS3 gene, a T786C polymorphism in the $5^{\prime}$ flanking region and the polymorphism on exon 7 that produces Glu $\rightarrow$ Asp amino acid substitution (Glu298Asp or G894T polymorphism) (Moncada et al. 1991, Nakayama et al. 1999).

Cigarette smoking is a major independent factor for the development of atherothrombotic vascular disease. Besides several other pathophysiological mechanisms, smoking also strongly deteriorates biological activity of endothelium-derived nitric oxide synthase (Antoniades et al. 2004). The aim of this study was to evaluate to potential interaction of genetically determined (i.e T786C and G894T polymorphisms) and exogenous (i.e. active smoking) alteration of NO metabolism in terms of increased arterial stiffness in generally healthy, middleaged untreated subjects.

\section{Methods}

The study population consisted of random general population sample. A survey of risk factors was undertaken in 2000-2001 as a part of Czech postMONICA study (Cífková et al. 2004). One percent of residents of City of Pilsen, aged 25-65 years, was selected (stratified by age and sex) from the General Health Insurance Registry. A total of 1009 subjects, 488 males and 522 females, mean age 48.1, responded to the survey. A random about $30 \%$ sub-sample was examined for mechanical properties of large arteries, but for purpose of present study all subjects with manifest cardiovascular disease (i.e. those with known coronary heart disease, history of stroke or lower-limb ischemic disease) or those chronically treated with antihypertensives, lipid-lowering drugs, antidiabetics or other pharmacotherapy, were excluded from final analyses.

All study procedures were done according to Good Clinical Practice regulation and were approved by the local Ethical Committee. The informed consent was obtained from all subjects and all personal data were stored under the provisions of the Czech Data Protection Act. All responders were interviewed and examined by standardized methods using WHO MONICA standard manual. Methods of interview were described in details elsewhere (Cífková et al. 2004). Briefly, information on personal and demographic characteristics, personal and family history of coronary heart disease, life-style and current pharmacotherapy were obtained at interview. Following standardized examinations were performed: height and weight in light indoor clothes without shoes by DETECTO 20 (Webb City, USA) scale and measuring stick. Blood pressure (BP) was measured three times in the sitting position on the right arm using standard mercury sphygmomanometers to the nearest $2 \mathrm{~mm} \mathrm{Hg}$; appropriate cuff size was used. The current smoking status, as reported by subject, was furthermore validated using Smokerlyser device (model III, Bedfont Scientific, Upchurch, UK).

Large artery properties were measured using the semi-automatic Sphygmocor device (AtCor Medical Ltd., 
Table 2. Pulse wave velocities (PWV) by eNOS polymorphism and smoking status. $p$ value by Mann-Whitney U test; mean \pm S.D.

\begin{tabular}{|c|c|c|c|c|}
\hline & peripheral PWV (m/s) & $\mathbf{p}$ & $\operatorname{aortic} \operatorname{PWV}(\mathrm{m} / \mathrm{s})$ & $\mathbf{p}$ \\
\hline \multicolumn{5}{|l|}{ T786C polymorphism } \\
\hline homo- or heterozygous carriers & $13.57 \pm 8.63$ & & $7.45 \pm 2.73$ & \\
\hline normal genotype carriers & $11.93 \pm 8.06$ & $<0.04$ & $7.26 \pm 1.99$ & 0.88 \\
\hline \multicolumn{5}{|l|}{ G894T polymorphism } \\
\hline homo- or heterozygous carriers & $13.01 \pm 6.60$ & & $7.58 \pm 2.84$ & \\
\hline normal genotype carriers & $12.71 \pm 9.99$ & $<0.01$ & $7.20 \pm 1.91$ & 0.35 \\
\hline \multicolumn{5}{|l|}{ Smoking } \\
\hline current smokers & $12.64 \pm 5.79$ & & $7.81 \pm 2.11$ & \\
\hline non-smokers & $13.32 \pm 9.62$ & 0.44 & $7.16 \pm 2.57$ & $<0.003$ \\
\hline
\end{tabular}

Australia); the methods of measurement was in detail described elsewhere (Mayer et al. 2006). Arterial stiffness was assessed by pulse wave velocity (PWV), measured in supine position in the aorta, i.e. between carotid and femoral arteries (aortic PWV, APWV), and in the lower extremity, i.e. between femoral and dorsalis pedis or tibialis posterior arteries (peripheral PWV, PPWV). Consecutive registrations of the pulse waves are ECG gated and thus, the time shift between the appearance of wave at the first and the second sites can be calculated. The distance between the two sites was measured on the body surface; to determine aortic PWV, we measured the distance from the jugular fossa to the pulsation of the femoral artery in the groin subtracting, from this distance, the distance from the jugular fossa to carotid pulsation since the pulse runs here in the direction opposite to that in the aorta. The average of measurements over a period of eight seconds (nine to ten cardiac cycles) was calculated after the exclusion of extreme values. The methods were shown to have good reproducibility (Wilkinson et al. 1998).

Venous blood samples were drawn in fasting state, and frozen serum samples, stored at $-80{ }^{\circ} \mathrm{C}$, were used for biochemical laboratory analyses in the series. The laboratory examinations, including assessment of total (TCHOL) and HDL cholesterol (HDL), triglycerides (TG) were provided by the central laboratories of survey (Institute of Clinical and Experimental Medicine, Prague) using Cobas Mira analyzer (Basel, Switzerland) and commercially available kits of the same provenience. Glucose levels (GLU) were analyzed by enzymatic method in the same laboratory using LACHEMA (Brno, Czech Republic) standard kits. LDL cholesterol (LDL) was calculated by Friedewald equation, i.e. $\mathrm{LDL}=$ TCHOL-HDL-(TG/5). Serum total homocysteine (tHcy) concentration was estimated by commercial FPIA kits and automatic analyzers (AxSYM, Abbott Laboratories, Wiesbaden, Germany). Variation for all these biochemical measurements was less than $1.5 \%$.

The eNOS gene polymorphisms were assessed by the polymerase chain reaction - restriction fragment length polymorphism methodology, as described elsewhere (Alvarez et al. 2001, Schneider et al. 2001). Genomic DNA was isolated from peripheral blood leucocytes by standard extraction method using commercial DNA isolation kits (Sigma, St. Louis, MO, USA). Two polymorphisms were assessed: T786C and G894T using REDTaq DNA polymerase (SIGMA), BanII (Eco24I) and MspI enzymes (Biogen, Prague, Czech Republic) and commercial primers.

The study was designed as a cross-sectional analysis. Statistical analysis of the data was done using STATA 6. The significance of differences among specific groups was evaluated by Fishers $\chi^{2}$ test for categorical variables and by analysis of variance (ANOVA) or Mann-Whitney U test for continuous variables. Multiple linear regression was used to ascertain the association between followed polymorphisms and PWVs after adjustment for potential confounders.

\section{Results}

A total of 194 subjects, 94 males and 100 females with mean age 45.7 years, were evaluated in the present study; other characteristics of the study sample are given in Table 1 . Among those, $36.1 \%$ subjects were current smokers; $14.4 \%$ ex-smokers were evaluated as non-smokers, because all ceased their smoking at least two years ago (median time between smoking cessation and examination was 5.5 years). The allele frequencies of 
Table 3. Conventional cardiovascular risk profile and pulse wave velocities according to polymorphism of endothelial nitric oxide synthase and current smoking status.

\begin{tabular}{|c|c|c|c|c|c|c|}
\hline & \multicolumn{3}{|c|}{ Smokers } & \multicolumn{3}{|c|}{ Non-smokers } \\
\hline & $\begin{array}{c}\text { homo- or } \\
\text { heterozygous }\end{array}$ & $\begin{array}{c}\text { normal } \\
\text { genotype }\end{array}$ & $\mathbf{p}$ & $\begin{array}{c}\text { homo- or } \\
\text { heterozygous }\end{array}$ & $\begin{array}{c}\text { normal } \\
\text { genotype }\end{array}$ & $\mathbf{p}$ \\
\hline \multicolumn{7}{|l|}{ T786C polymorphism } \\
\hline$n$ & 42 & 28 & & 68 & 56 & \\
\hline Age (years) & $44.4 \pm 10.27$ & $47.3 \pm 10.57$ & 0.27 & $46.0 \pm 11.24$ & $44.4 \pm 11.1$ & 0.72 \\
\hline Gender (\% of males) & 64.3 & 53.6 & 0.46 & 42.6 & 41.1 & 0.88 \\
\hline Body mass index $\left(\mathrm{kg} / \mathrm{m}^{2}\right)$ & $25.6 \pm 4.22$ & $26.2 \pm 4.13$ & 0.44 & $25.8 \pm 4.01$ & $26.6 \pm 4.10$ & 0.24 \\
\hline Systolic BP (mm Hg) & $123.8 \pm 15.68$ & $125.6 \pm 15.7$ & 0.67 & $122.2 \pm 15.11$ & $122.2 \pm 15.32$ & 0.81 \\
\hline Diastolic BP (mm Hg) & $79.9 \pm 8.83$ & $75.8 \pm 8.20$ & $<0.038$ & $79.3 \pm 10.13$ & $79.9 \pm 9.65$ & 0.71 \\
\hline Total cholesterol $(\mathrm{mmol} / \mathrm{l})$ & $5.83 \pm 1.10$ & $6.18 \pm 1.43$ & 0.31 & $5.59 \pm 1.12$ & $5.72 \pm 1.10$ & 0.70 \\
\hline LDL-cholesterol (mmol/l) & $3.66 \pm 0.95$ & $3.90 \pm 1.12$ & 0.36 & $3.49 \pm 1.01$ & $3.54 \pm 1.01$ & 0.85 \\
\hline HDL-cholesterol $(\mathrm{mmol} / \mathrm{l})$ & $1.37 \pm 0.39$ & $1.50 \pm 0.38$ & 0.15 & $1.47 \pm 0.40$ & $1.47 \pm 0.34$ & 0.95 \\
\hline Triglycerides (mmol/l) & $1.75 \pm 0.91$ & $1.62 \pm 0.91$ & 0.59 & $1.47 \pm 0.66$ & $1.60 \pm 1.02$ & 0.76 \\
\hline Fasting glucose (mmol/l) & $5.41 \pm 0.52$ & $5.97 \pm 2.38$ & 0.30 & $5.27 \pm 0.42$ & $5.40 \pm 0.54$ & 0.19 \\
\hline Total homocysteine $(\mu \mathrm{mol} / \mathrm{l})$ & $12.6 \pm 5.62$ & $11.5 \pm 2.91$ & 0.97 & $11.3 \pm 4.14$ & $10.6 \pm 3.84$ & 0.15 \\
\hline Peripheral PWV $(\mathrm{m} / \mathrm{s})$ & $13.98 \pm 6.71$ & $10.68 \pm 3.12$ & $<0.002$ & $13.30 \pm 9.72$ & $12.56 \pm 9.57$ & 0.93 \\
\hline Aortic PWV $(\mathrm{m} / \mathrm{s})$ & $7.58 \pm 2.05$ & $8.13 \pm 2.20$ & 0.32 & $7.36 \pm 3.10$ & $6.92 \pm 1.77$ & 0.58 \\
\hline \multicolumn{7}{|l|}{ G894T polymorphism } \\
\hline$n$ & 41 & 29 & & 58 & 66 & \\
\hline Age (years) & $45.1 \pm 10.76$ & $46.2 \pm 10.04$ & 0.68 & $45.3 \pm 10.79$ & $46.1 \pm 11.52$ & 0.75 \\
\hline Gender (\% of males) & 63.4 & 55.2 & 0.56 & 41.4 & 42.4 & 0.92 \\
\hline Body mass index $\left(\mathrm{kg} / \mathrm{m}^{2}\right)$ & $26.1 \pm 4.26$ & $25.4 \pm 4.07$ & 0.58 & $26.0 \pm 3.93$ & $26.3 \pm 4.19$ & 0.94 \\
\hline Systolic BP (mm Hg) & $124.0 \pm 15.74$ & $125.2 \pm 15.66$ & 0.74 & $122.9 \pm 16.02$ & $121.6 \pm 14.41$ & 0.64 \\
\hline Diastolic BP (mm Hg) & $79.4 \pm 9.57$ & $76.7 \pm 7.37$ & 0.20 & $80.9 \pm 10.15$ & $78.4 \pm 9.52$ & 0.15 \\
\hline Total cholesterol (mmol/l) & $5.79 \pm 1.32$ & $6.21 \pm 1.09$ & 0.12 & $5.69 \pm 1.08$ & $5.61 \pm 1.14$ & 0.66 \\
\hline LDL-cholesterol (mmol/l) & $3.59 \pm 1.03$ & $3.98 \pm 0.98$ & 0.10 & $3.47 \pm 0.99$ & $3.55 \pm 1.03$ & 0.80 \\
\hline HDL-cholesterol $(\mathrm{mmol} / \mathrm{l})$ & $1.39 \pm 0.37$ & $1.48 \pm 0.41$ & 0.32 & $1.51 \pm 0.38$ & $1.44 \pm 0.36$ & 0.43 \\
\hline Triglycerides (mmol/l) & $1.72 \pm 1.03$ & $1.66 \pm 0.72$ & 0.79 & $1.55 \pm 0.90$ & $1.50 \pm 0.81$ & 0.52 \\
\hline Fasting glucose (mmol/l) & $5.43 \pm 0.57$ & $5.93 \pm 2.33$ & 0.53 & $5.31 \pm 0.46$ & $5.35 \pm 0.50$ & 0.88 \\
\hline Total homocysteine $(\mu \mathrm{mol} / \mathrm{l})$ & $12.4 \pm 4.90$ & $12.0 \pm 4.57$ & 0.67 & $11.1 \pm 4.42$ & $10.87 \pm 3.63$ & 0.99 \\
\hline Peripheral PWV $(\mathrm{m} / \mathrm{s})$ & $13.88 \pm 6.96$ & $11.04 \pm 3.12$ & $<0.015$ & $12.40 \pm 6.34$ & $13.47 \pm 11.85$ & 0.19 \\
\hline Aortic PWV $(\mathrm{m} / \mathrm{s})$ & $7.79 \pm 2.26$ & $7.82 \pm 1.91$ & 0.88 & $7.44 \pm 3.20$ & $6.93 \pm 1.85$ & 0.37 \\
\hline
\end{tabular}

p value by Mann-Whitney U test; BP - blood pressure; LDL - low density lipoprotein; HDL - high-density lipoprotein; PWV - pulse wave velocity; mean \pm S.D.

the two polymorphisms studied were in equilibrium according to the Hardy-Weinberg distribution (Table 1).

Associations between PWVs and eNOS polymorphisms or smoking are given in Table 2. Carriers of at last one $\mathrm{C}$ allele from T786C polymorphism showed significantly higher peripheral PWV (PPWV) than carriers of normal TT genotype and the similar were found for G894T polymorphism. On the other hand, no such differences were found in aortic PWV (APWV). Current smokers showed significantly higher APWW than nonsmokers, while there were no differences in PPWV.

The whole sample was furthermore divided according to the current smoking status and the differences by eNOS polymorphisms (normal genotype carriers versus homo- or heterozygous carriers) were evaluated (Table 3). Current smokers carrying mutant $\mathrm{C}$ allele from T786C 
Table 4. Multiple stepwise regressions of peripheral pulse wave velocity (increase by $3 \mathrm{~m} / \mathrm{s}$ ), both polymorphisms of eNOS (in two different models) and conventional risk factors as potential confounders in smokers and non-smokers (odds ratio (95\% confidence intervals)).

\begin{tabular}{|c|c|c|c|c|c|c|}
\hline & $\begin{array}{l}\text { Model A } \\
\text { smokers }\end{array}$ & p value & $\begin{array}{l}\text { Model B } \\
\text { smokers }\end{array}$ & p value & $\begin{array}{c}\text { Model C } \\
\text { non-smokers }\end{array}$ & p value \\
\hline$T 786 C^{*}$ & $1.40(1.13-1.75)$ & $<0.004$ & not included & & - & \\
\hline$G 894 T^{*}$ & not included & & $1.39(1.09-1.77)$ & $<0.005$ & - & \\
\hline Age & $1.15(0.91-1.45)$ & 0.25 & $1.14(0.90-1.44)$ & 0.27 & $1.17(0.97-1.41)$ & 0.11 \\
\hline Gender & $1.34(1.06-1.69)$ & $<0.02$ & $1.32(1.04-1.67)$ & $<0.03$ & $1.11(0.18-6.69)$ & 0.26 \\
\hline$B M I$ & $0.80(0.62-1.02)$ & 0.07 & $0.71(0.55-0.90)$ & $<0.008$ & $0.85(0.13-5.69)$ & 0.10 \\
\hline$M A P$ & $1.17(0.91-1.50)$ & 0.22 & $1.23(0.96-1.57)$ & 0.11 & $1.17(0.96-1.43)$ & 0.12 \\
\hline$L D L$ & $1.34(1.06-1.70)$ & $<0.02$ & $1.41(1.10-1.80)$ & $<0.008$ & - & \\
\hline Triglycerides & $0.77(0.60-1.00)$ & 0.05 & $0.81(0.62-1.05)$ & 0.11 & - & \\
\hline Glycemia & $0.83(0.67-1.04)$ & 0.12 & $0.83(0.67-1.04)$ & 0.11 & - & \\
\hline
\end{tabular}

OR, odds ratio; $\mathrm{CI}$, confidence intervals; BMI - body mass index; MAP - mean arterial pressure, homo- or heterozygous carriers; increase of peripheral PWV by $3 \mathrm{~m} / \mathrm{s}$ as dependent variable; following independent variables were included into full models: age, gender, body mass index, mean arterial pressure, LDL-cholesterol, triglycerides, fasting glycemia, total homocysteine (all as continuous variables) and homo- or heterozygosity for T786C or G894T polymorphisms.

polymorphism showed significantly higher PPWV than subjects with normal TT genotype. In contrast, PPWV did not differ by T786C polymorphism in non-smokers. Similar patterns were found by G894T polymorphism. Except lower diastolic BP in smokers with normal TT genotype in T786C polymorphism, there were no differences in other potentially confounding factors by polymorphisms, either in smokers or non-smokers, and the results for APWV were completely negative (Table 3). The independency of association between both eNOS polymorphisms and PPWV was confirmed by multiple step-wise linear regression (Table 4). Taking increase of PPWV by $3 \mathrm{~m} / \mathrm{s}$ as dependent variable, homo- or heterozygosity for T786C, gender and LDL cholesterol significantly entered the regression as independent variables (model A), whereas homo- or heterozygosity for G894T, gender, body mass index and LDL cholesterol in the model B. In contrast, the polymorphisms did not enter the similar regression (model C) among non-smokers and moreover, no such associations were found in APWV. The effect of combination of both eNOS polymorphisms in one subject was analyzed in Figure 1. A significant trend to higher PPWV was found with increasing number of mutant alleles of both studied polymorphisms, but only in current smokers again.

\section{Discussion}

In our cross-sectional study we found that currently smoking carriers of either T786C or G894T polymorphisms, free of any form of manifest vascular disease and without any chronic pharmacotherapy, showed significantly higher stiffness of peripheral, medium-sized, muscular type arteries, than carriers of normal eNOS genotype. In contrast, non-smokers did not show any differences in peripheral arterial stiffness by both eNOS polymorphisms and similarly smoking alone did not influence the PPWV in subjects with normal genotype. Subjects carrying both polymorphisms (T786C and G894T) in combination and having at least one in homozygous state showed higher PPWV than those without any mutant allele, but this difference reached statistical significance only in current smokers.

The role of $\mathrm{NO}$ in arterial stiffness was demonstrated by several studies. However there was a marked difference between muscular-type and elastic-type arteries. In muscular arteries, stiffness is influenced by mean arterial pressure, as a determinant of transmural distending pressure, and by tone of arterial smooth muscle, a functional determinant of arterial elasticity. It is evident, that elasticity of muscular-type arteries is sensitive to changes in smooth muscle tone induced by NO. Bank et al. (1999) reported that NO donor nitroglycerine increased elasticity (or decreased stiffness) of muscular-type brachial artery in vivo, independently of transmural pressure. Kinlay et al. (2001) reported that acute inhibition of basal NO release by specific inhibitor $\mathrm{N}^{\mathrm{G}}$-monomethyl-Larginine (L-NAME) resulted in the decreased elasticity of 


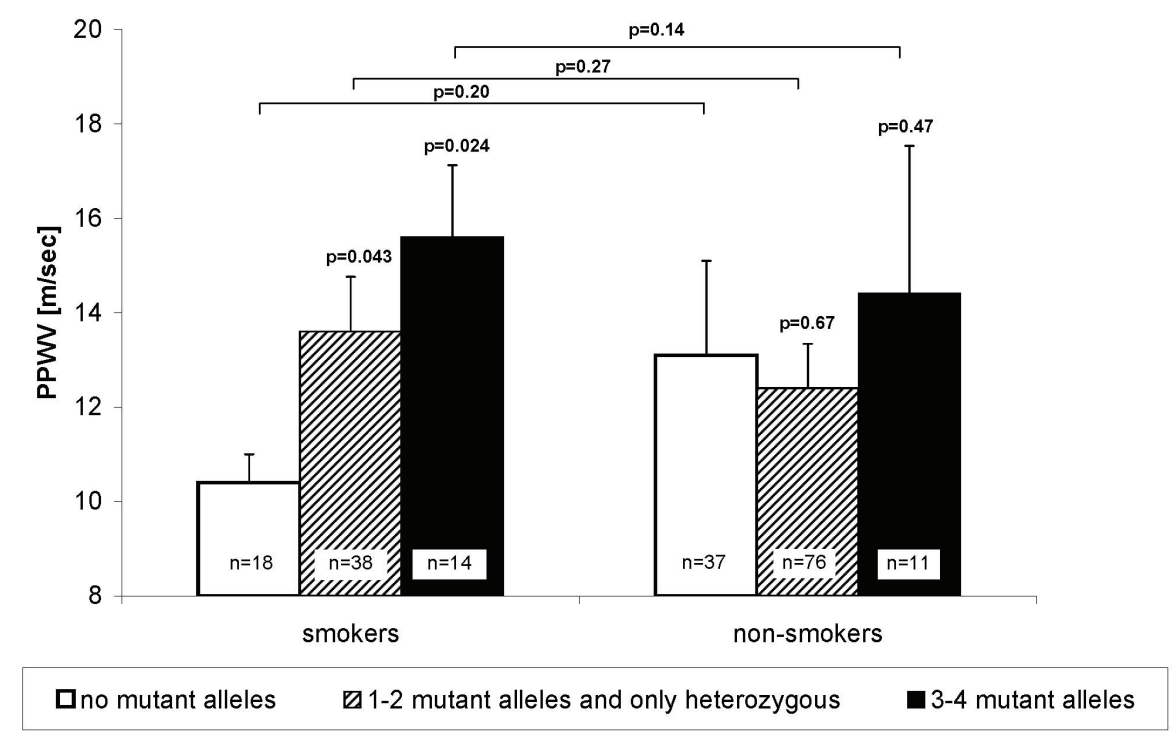

Fig. 1. Peripheral pulse wave velocity (PPWV) by intra-individual combination of T786C or G894T polymorphisms: white bar - no mutant allele from both polymorphisms; stripped bar - 1-2 mutant alleles, but only in heterozygous carriers (i.e. subjects with at least one or both polymorphisms in heterozygous state); black bars - 3 to 4 mutant alleles (i.e. subjects with both polymorphisms in homozygous state or one in homozygous and the second in heterozygous state); $\mathrm{p}$ value adjusted for age (mean \pm S.E.M.).

brachial artery, whereas nitroglycerine reversed this effect. In contrast, elastic-type artery properties probably depend only marginally on NO release. The human aorta is rich on elastin and with advancing age, relative amount of collagen increases. The amount of smooth muscle is lower that in muscular type arteries; smooth muscle cells are present in abdominal segment of aorta. Stewart et al. (2003) reported that L-NAME infusion increased aortic stiffness in vivo, and this effect depended on blood pressure changes (transmural pressure) but not on smooth muscle tone. On the other hand, the effect of NO release on elasticity could already be demonstrated on musculoelastic (ovine) iliac artery (Wilkinson et al. 2002). Our results are in line with these studies, because we observed the association between eNOS polymorphisms and arterial stiffness only in peripheral (muscular-type), but not in central elastic arteries.

Smoking represents a major exogenous factor affecting endothelial function. Antoniades et al. (2004) reported an impaired endothelial function in smokers compared to healthy subjects using flow-mediated vasodilation technique. The acute effect of smoking on arterial stiffness was studied by Siasos et al. (2007). In this study, smoking induced a rapid elevation of PWV, which persisted for at least $20 \mathrm{~min}$. Moreover, pretreatment with L- arginine, a substrate of eNOS, partly prevented this smoking-induced increase in PWV. Another study demonstrated that chronic treatment with L-arginine improved the arterial stiffness in healthy subjects (Miller 2006).

To our knowledge, the mutual association between smoking, eNOS polymorphism and stiffness of muscular-type arteries has not yet been thoroughly studied. The only study (Woodside et al. 2004) failed to find any differences in PWVs between smokers and nonsmokers and by G894T polymorphism (as done in this study). However, their methodological approach (PWV measurement between carotid and dorsalis-pedis arteries) unfortunately summarized stiffness of elastic and muscular-type vascular bed (with totally different properties) into one parameter, which may bias the association studied.

In spite of biological plausibility, the causality of eNOS polymorphism in etiology of vascular diseases remains controversial. Tsujita et al. (2001) failed to demonstrate any association between hypertension and both eNOS polymorphisms in large sample of Japanese population. In contrast, another study done on Japanese population reported the positive association of G894T polymorphism and hypertension (Miyamoto et al. 1998). Similarly, several case-control studies found a positive association between eNOS polymorphisms and myocardial infarction, while another studies showed negative results (Shimasaki et al. 1998, Wang et al. 2001, Rossi et al. 2003).

In conclusion, in our sample of healthy untreated subjects from general population, genetically determined impairment of NO metabolism resulted in increased stiffness of muscular type arteries, but only in interaction with current smoking.

\section{Conflict of Interest}

There is no conflict of interest.

\section{Acknowledgements}

The present study was founded by Internal Grant Agency 
of Czech Ministry of Health (grant no. 9333-3), by Ministry of Education (grant no. 0021620819), by InGenious HyperCare project (6th Framework Program of the EU) and by HYPERGENES project (7th
Framework Program of the EU). We also used several data from post-MONICA study, therefore we would like to acknowledge the cooperation of all investigators who participated on this survey.

\section{References}

ALVAREZ R, GONZÁLEZ P, BATALlA A, REGUERO JR, IGLESIAS-CUBERO G, HEVIA S, CORTINA A, MERINO E, GONZÁLEZ I, ALVAREZ V, COTO E: Association between the NOS3 (-786 T/C) and the ACE (I/D) DNA genotypes and early coronary artery disease. Nitric Oxide 5: 343-348, 2001.

ANTONIADES C, TOUSOULIS D, VASILIADOU C, MARINOU K, TENTOLOURIS C, NTARLADIMAS I, STEFANADIS C: Combined effects of smoking and hypercholesterolemia on inflammatory process, thrombosis/fibrinolysis system, and forearm hyperemic response. Am J Cardiol 94: 1181-1184, 2004.

BANK AJ, KAISER DR, RAJALA S, CHENG A: In vivo human brachial artery elastic mechanics: effects of smooth muscle relaxation. Circulation 100: 41-47, 1999.

CÍFKOVÁ R, ŠKODOVÁ Z, LÁNSKÁ V, ADÁMKOVÁ V, NOVOZÁMSKÁ E, PETRŽÍLKOVA Z: Trends in blood pressure levels, prevalence, awareness, treatment, and control of hypertension in the Czech population from 1985 to 2000/01. J Hypertens 22: 1479-1485, 2004.

JANSSENS SP, SHIMOUCHI A, QUETERMOUS T, BLOCH DB, BLOCH KD: Cloning and expression of cDNA encoding human endothelium-derived relaxing factor/nitric oxide synthase. J Biol Chem 267: 14519-14522, 1992.

KINLAY S, CREAGER MA, FUKUMOTO M, HIKITA H, FANG JC, SELWYN AP, SELWYN AP, GANZ P: Endothelium-derived nitric oxide regulates arterial elasticity in human arteries in vivo. Hypertension 38: 10491053, 2001.

LAURENT S, BOUTOUYRIE P, ASMAR R, GAUTIER I, LALOUX B, GUIZE L, DUCIMETIERE P, BENETOS A: Aortic stiffness is an independent predictor of all-cause and cardiovascular mortality in hypertensive patients. Hypertension 37: 1236-1241, 2001.

LOCALZO J, WELCH G: Nitric oxide and its role in the cardiovascular system. Prog Cardiovasc Dis 38: 87-104, 1995.

MAYER O, FILIPOVSKÝ J, DOLEJŠOVÁ M, CÍFKOVÁ R, ŠIMON J, BOLEK L: Mild hyperhomocysteinaemia is associated with increased aortic stiffness in general population. J Hum Hypertens 20: 267-271, 2006.

MEAUME S, BENETOS A, HENRY OF, RUDNICHI A, SAFAR ME: Aortic pulse wave velocity predicts cardiovascular mortality in subjects >70 years of age. Arterioscler Thromb Vasc Biol 21: 2046-2050, 2001.

MILLER AL: The effects of sustained-release-L-arginine formulation on blood pressure and vascular compliance in 29 healthy individuals. Altern Med Rev 11: 23-29, 2006.

MIYAMOTO Y, SAITO Y, KAJIYAMA N, YOSHIMURA M, SHIMASAKI Y, NAKAYAMA M, KAMITANI S, HARADA M, ISHIKAWA M, KUWAHARA K, OGAWA E, HAMANAKA I, TAKAHASHI N, KANESHIGE T, TERAOKA H, AKAMIZU T, AZUMA N, YOSHIMASA Y, YOSHIMASA T, ITOH H, MASUDA I, YASUE H, NAKAO K: Endothelial nitric oxide synthase gene is positively associated with essential hypertension. Hypertension 32: 3-8, 1998.

MONCADA S, PALMER RM, HIGGS EA: Nitric oxide: physiology, pathophysiology, and pharmacology. Pharmacol Rev 43: 109-142, 1991.

NAKAYAMA M, YASUE H, YOSHIMURA M, SHIMASAKI Y, KUGIYAMA K, OGAWA H, MOTOYAMA T, SAITO Y, OGAWA Y, MIYAMOTO Y, NAKAO K: T $\rightarrow 786 \mathrm{C}$ mutation in the 5'-flanking region of the endothelial nitric oxide synthase gene is associated with coronary spasm. Circulation 99: 2864-2870, 1999.

ROSSI GP, CESARI M, ZANCHETTA M, COLONNA S, MAIOLINO G, PEDON L, CAVALLIN M, MAIOLINO P, PESSINA AC: The T-786C endothelial nitric oxide synthase genotype is a novel risk factor for coronary artery disease in Caucasian patients of the GENICA study. J Am Coll Cardiol 41: 930-937, 2003. 
SCHNEIDER MP, ERDMANN J, DELLES C, FLECK E, REGITZ-ZAGROSEK V, SCHMIEDER RE: Functional gene testing of the Glu298Asp polymorphism of the endothelial NO synthase. J Hypertens 18: 1767-1773, 2001.

SHIMASAKI Y, YASUE H, YOSHIMURA M, NAKAYAMA M, KUGIYAMA K, OGAWA H, HARADA E, MASUDA T, KOYAMA W, SAITO Y, MIYAMOTO Y, OGAWA Y, NAKAO K: Association of the missense Glu298Asp variant of the endothelial nitric oxide synthase gene with myocardial infarction. $J \mathrm{Am}$ Coll Cardiol 31: 1506-1510, 1998.

SIASOS G, TOUSOULIS D, VLACHOPOULOS C, ANTONIADES C, STEFANADI E, IOAKEIMIDIS N, ANDREOU I, ZISIMOS K, PAPAVASSILIOU AG, STEFANADIS C: Short-term treatment with L-arginine prevents the smoking-induced impairment of endothelial function and vascular elastic properties in young individuals. Int J Cardiol 126: 394-399, 2008.

STEWART AD, MILLASSEAU SC, KEARNEY MT, RITTER JM, CHOWIENCZYK PJ: Effects of inhibition of basal nitric oxide synthesis on carotid-femoral pulse wave velocity and augmentation index in humans. Hypertension 42: 915-918, 2003.

TSUJITA Y, BABA S, YAMAUCHI R, MANNAMI T, KINOSHITA M, YAMAMOTO R, KATSUYA T, HIGAKI J, OGIHARA T, OGATA J, IWAI N: Association analyses between genetic polymorphisms of endothelial nitric oxide synthase gene and hypertension in Japanese: the Suita Study. J Hypertens 19: 1941-1948, 2001.

WANG CL, HSU LA, KO YS, KO YL, LEE YH: Lack of association between the Glu298Asp variant of the endothelial nitric oxide synthase gene and the risk of coronary artery disease among Taiwanese. $J$ Formos Med Assoc 100: 736-740, 2001.

WILKINSON IB, FUCHS SA, JANSEN IM, SPRATT JC, MURRAY GD, COCKCROFT JR, WEBB DJ: Reproducibility of pulse wave velocity and augmentation index measured by pulse wave analysis. $J$ Hypertens 16: 2079-2084, 1998.

WILKINSON IB, QASEM A, MCENIERY CM, WEBB DJ, AVOLIO AP, COCKCROFT JR: Nitric oxide regulates local arterial distensibility in vivo. Circulation 105: 213-217, 2002.

WOODSIDE JV, MCMAHON R, GALLAGHER AM, CRAN GW, BOREHAM CA, MURRAY LJ, STRAIN JJ, MCNULTY H, ROBSON PJ, BROWN KS, WHITEHEAD AS, SAVAGE M, YOUNG IS: Total homocysteine is not a determinant of arterial pulse wave velocity in young healthy adults. Atherosclerosis 177: 337-344, 2004. 